\title{
Analysing Text for Translation: Genesis of Stylistic Categories for Comparing Language Pairs
}

\author{
Sushant Kumar Mishra \\ Professor, Centre for French and Francophone Studies, School of Language, Literature and \\ Culture Studies, Jawaharlal Nehru University. \\ Emails: sushantkmishra@mail.jnu.ac.in, sushantjnu@gmail.com
}

\begin{abstract}
:
Translation related issues have been explored since times immemorial in various societies of the world. Transferring language-based knowledge systems and experiences have been an exclusive faculty of the human species. Paraphrasing vs metaphrasing in translating texts have been important concerns of translators while expressing the thoughts in texts of language into another language. Should there be a politics of these two approaches being applied as per the ideological requirements? In the background of this question, we need to understand how and why the successors of Saussure continued working on the stylistic categories of expressions of ordinary language usages while often comparing the two language pairs also in the context of style and translation. The presentation aims to explore the translation theories in the context of the ideological requirements of their times and continues to understand the comparative stylistic categories of Saussure's successors which are useful in practically translating a text.
\end{abstract}

Keywords: Stylistic Categories, Translation, Language Pairs, text, metaphrastic styles

Translation related issues have been explored since times immemorial in various societies of the world. Transferring language-based knowledge systems and experiences have been an exclusive faculty of the human species. Paraphrasing vs metaphrasing in translating texts have been important concerns of translators while expressing the thoughts in texts of language into another language. Should there be a politics of these two approaches being applied as per the ideological requirements? In the background of this question, we need to understand how and why the successors of Saussure continued working on the stylistic categories of expressions of ordinary language usages while often comparing the two language pairs also in the context of style and translation. The presentation aims to explore the translation theories in the context of the ideological requirements of their times and continues to understand the comparative stylistic categories of Saussure's successors which are useful in practically translating a text.

Language and linguistic diversity are important features of human beings. Other animals may have the same ways of communication across the geographically varied locations. Human beings vary in their sound-based communication systems which exhibit very intricate and elaborate formation. This variation in the communication code systems of human beings have historically given rise to the need to expressing in one code system of human communication what is expressed

(c) AesthetixMS 2021. This Open Access article is published under a Creative Commons Attribution Non-Commercial 4.0 International License (http://creativecommons.org/licenses/by-nc/4.o/), which permits non-commercial re-use, distribution, and reproduction in any medium, provided the original work is properly cited. For citation use the DOI. For commercial re-use, please contact editor@rupkatha.com. 
in another code system. In spite of the variations, human beings needed and perhaps will always need to communicate with each other across linguistic communities. Such requirements, as ordained by the historical situations and recorded historically available narratives, have been mentioned and theorized in numerous ways across times and space. In the Oriental civilizations (read Indian and cultural spaces east to India) have understood the issues of the cross-linguistic communications differently than the Occidental thinkers. We will try to understand such differences and will further explore how the stylistic categories have evolved in these two geographical regions. In this paper, we will try to understand first the differences in the processes of translation between the Oriental and the Occidental cultures and then we will try to understand the stylistic categories for understanding translation as these stylistic categories appear to have evolved in European traditions due to the interactions with the Indian traditions.

The cultural spaces east to India and within the Indian subcontinent have since times immemorial lives various linguistic experience with languages divergences spanning over various language families. Within the same language families, a lot of diversity exists. Various Prakrit forms during various periods of history attest to the divergence that existed across the Indian subcontinent. The interaction with countries like Indonesia, Malaysia, Cambodia, Thailand etc. have also brought richness to the cultural experiences within Indian knowledge systems triggered by the linguistic experiences of these cultures which have similarities with what we find in various parts of India. Linguistic studies have established the relationship between the Indian languages and the languages of various East Asian countries. Interactions over various cultural forms related to Buddhism and ordinary life requirements might have brought all these countries closer to each other in past. In the process the language interactions and translations must have happened in diverse forms. Texts and language expressions would have travelled from one place to the other as has happened. Such interactions have been part of human history since times immemorial. It is thus but natural that human beings have thought over the language interactions as have happened in various parts of the world. In the context of translation, we may notice different ways of translating and sometimes different theorizations on translation processes.

One of the most important distinctions made in theories of translation is about metaphrasing and paraphrasing as elaborated by various thinkers like Longinus, Pope, Dryden and several others till date. As Susan Basnett writes, "...the distinction between word for word and sense for sense translation, established within the Roman system, has continued to be a point for debate in one way or another right up to the present..." (2002, pp. 45). Basnett has clearly underlined the importance of these two methods of translation. Other thinkers like Etienne Dolet considers this point while explaining various rules for the art of translation. In the third rule, he considers, "Le tiers oinct est, qu'en traduisant il ne se fault pas asseruir iusques à la, que l'on rende mot pour mot. Et si aulcun le faict, cela luy procede de pauureté, \& deffault d'esprit.» (n.d. pp. 5)This passage, in old French which is not yet available in modern French, may be roughly translated as « The third rule of the translation is that the translation should not render the text word to word. If someone does so, it shows the poverty and lack of his intelligence". Numerous European authors may be cited for favouring the paraphrastic method of translation to the metaphrastic practices. We may even conjecture that almost in the entire history of the Euro-American tradition of translation, metaphrasing has been rejected with derision.

The Eastern cultures, mainly Indian and the cultures east to India, have perhaps a different response to the issue of metaphrasing and paraphrasing. Though explicit theorization may not be available by the thinkers, their act of translation exhibits their idea of translation. We may look at this issue in two different ways - (i) translation or rather recreation of the metanarrative texts 
within the Indian traditions (ii) translation or rather transmission of textual knowledge (of various fields) within Indian tradition and towards the countries towards east to India. We have proof of such transmission of textual knowledge towards west to India also - however, most of such texts are not available to us in present times. Some texts like Panchtantra and similar literary narratives can be traced in Persian and Arabic traditions. Yet, full texts of philosophical, mathematical or of other branches of knowledge are generally not available to us in the Perso-Arabic or Greco-Latin traditions. Hence, it is difficult to assess how the texts were rendered in the languages west to India while transmitting the knowledge systems.

Let us try to understand the processes of recreation of metanarrative texts within the Indian traditions. This happened between Sanskrit and Prakrit forms interchangeably. Both the language forms were used within same texts and the narratives, though the main story line bear similarity, changes in their narrative techniques as well as in the treatment of the narrative. In the context of translation studies, we may argue that they are translation so the same text and we may argue just the opposite of this point of view. The seemingly opposite points of view emanate perhaps from the two bipolar views on the translation - whether for the translation, there is always one primary text or there is always a metanarrative whose various renderings may be considered translations. Within the Indian traditions, it may be often very difficult to identify one such primary text which has been rendered in varied forms time and again. For example, it may be difficult to identify the 'original text of Ramayana' in the Indian languages. We have a tradition that considers Valmiki to the first poet and he could feel the pathos desired for narrating the story of Ramayana. Yet, we have a Ramayana written by Vyasa which is called Adhyatma Ramayana. Historically, it may be difficult to identify which one is prior to the other. Vyasa has been associated to the Vedas also and Vedas are considered the first texts in Sanskrit. Even Tulasidas in Ramacharitamanas (one of the most popular versions of Ramayana) states the following two verses: Vande visuddhavijnani kavisvarakapisvarau (verse 4 of the Sloka in the beginning of Ramacharitamanas) and Nanapurananigamagamasammatam yad ramayane nigaditam kvacidanyatopi (from the $7^{\text {th }}$ verse of the Sloka in the beginning of Ramacharitamanas). In the verse 4, Tulasidas pays his obeisance to 'kavisvar' and 'kapisvar' together. Here 'kavisvar' will be understood as Valmiki in the context. This indicates that Tulasidas refers to the Ramayana written by Valmiki. Further he indicates clearly in the $7^{\text {th }}$ verse cited above that he refers to various Purana, Nigama, Agam texts and narrates the story in accordance with all these texts. He counts Ramayana also in this list of his sources. Thus there is not one single source of the text. And scholars often indicate some originality in the narrative of Tulasidas not only in narrative techniques but also in the story line of the text. The title of the text itself indicates that it is not simply the narration of the story. 'Charita' may be understood as the 'life events' of Ram. 'Manas' may be understood as 'essence' (heart and mind) and also as the metaphor for the pure lake near the mountain Kailash. The title would suggest that the text presents the 'essence of the story of the life of Rama' and the 'text itself presents the vastness and natural beauty of the story like the Himalayan lake'. This allusion to the 'essence' and the 'vastness' indicates that the poet has tried to include the essence of all the possible Rama stories till his time. As a true devotee-poet, he considers the subject matter of the text pure as every text, with all the natural interpolations of ideas and sources from texts as well as in the folk, is pure in its own existence. Thus the title indicates the vision of the poetic vision of Tulasidas while creating this text - this includes the interpolations, intertextuality as natural to the poetic process while maintaining the sanctity of the text he has created. In this sense, Ramcharitmanas of Tulasidas may not be considered a translation. Yet, if we understand every act of translation as an act of transcreation, we may argue that the text is a Translation of Valmiki's Ramayan with interpolations from other versions of the story of Ramayana available to the poet. In the folk, often Tulasidas is considered an 
incarnation of Valmiki. Considering Tulasidas an incarnation of Valmiki indicates the process of reception of his text by people. This reception, one may argue, also may imply that the text of Tulasidas would fall into the category of translation adapted to the receptive literary environment of his age. We may find similar processes of recreation of various metanarrative texts within the Indian languages and within the Indian traditions.

If we look at the transmission of knowledge systems outside India, the process may be different. First of all, the texts are of different nature. They are mostly philosophical or philosophicreligious texts. The translation projects have been undertaken mostly with the view to understand the ideas in the text. The purpose is not to transfer the ideas to a reader who is not initiated in this system though well versed in another system of thought. Most of the texts transmitted to the countries east of India (Thailand, Tibet, China, Korea, Japan etc.) have adopted the 'paraphrastic techniques' in their own way. They have not tried to translate the meaning of the text. Either they have learnt the language, or they have adapted the language or they have translated the text literally word to word and then evolved a tradition of explaining the meaning of the text. Though this proposition need to be elaborated in details and requires extensive collaborative work with scholars of various traditions of translation and reception of Indian texts in these linguistic areas, as an evidence, I present here one citation from the Introduction of the translation of Ashvaghosha's Buddhacaritam by Edward B. Cowell. Cowell writes, "The Tibetan version appears to be much closer to the original Sanskrit than the Chinese; in fact from its verbal accuracy we can often reproduce the exact words of the original, since certain Sanskrit words are always represented by the same Tibetan equivalents, as for instance, the prepositions prefixed to verbal roots. I may here express an earnest hope that we may ere long have an edition and translation of the Tibetan version, if some scholar can be found to complete Dr. Wendzel's unfinishedlabour..." (n.d.). This citation cites an instance of the linguistic process of the treatment of language pair Sanskrit - Tibetan for translation. Several other such instances may be found from various sources in Hindi, English and other languages. It is important to note here that Cowell hints at the 'reproduction of the exact words of the original' through their Tibetan equivalents. This implies that the new words, new word formations have happened in Tibetan while translating from Sanskrit. The attempt of the translator is perhaps to render the text in Tibetan as close to the original as possible even if neologism has to be created in the target language. In such an effort of the translator, we may notice the attempt to understand the original text as closely as possible. There is perhaps no requirement to transfer the text but to transfer the meaning and the philosophical concepts with the contexts in which the text has to be understood. If we juxtapose this spirit of enquiry into the translation process of the text with the earlier cited process of preference to the metaphrastic translation of the text (as we notice in most of the cultures west to India), we may notice that it is the purpose of the translation which makes the process different.

Paraphrastic translations are preferred by those who make an attempt to understand the text, the context, the tradition of the text as close as possible to the source language and the source culture. Metaphrastic translations are preferred by those who make an attempt to understand the text in their own context while only referring to the original tradition of the text in the source language. So, in the metaphrastic translations, the original yields to the transferred and subsequently received form of the text. The word 'translation' (trans + fero, ferre, tuli, latus : latus is the conjugation in the perfective aspects which is retained in the word 'translation') itself suggest that the text has to be carried across, not necessarily the idea as found in the original. That is perhaps a reason why the Eastern Cultures did not have the exact word for translation - while 'transferring' the text, their attempt was to transfer not only the text, but also the idea as found in the original. The texts like 'Lotus Sutra' are known by almost the same title that we find in the 
original Saddharma Pundarika. We may conjecture here that these two traditions different substantially in their approach due to the political and social contexts in which they were operating. It is interesting to note that the Greeks have not theorized on the translation in spite of the tradition of the translation of the Old Testament from Hebrew to Greek. They justified the translation by religiously evolving the story of 'seventy different translations' which were exactly the same of the original Hebrew text. Yet, no Greek thinker appears to have theorized on the process of the translation. Perhaps the Greeks had also the similar views as we find in the cultures east to India and within Indian subcontinent. The Latin and other continental thinkers mostly belonged to an Empire or at least to a religious culture which considered proselytisation and religious-cumpolitical unification of the other cultures an important aspect of their thought processes. This is not so with the Greeks nor with the cultures recipient of the Indian texts or evolution of the texts further in their own cultures. There was no project related to the Empire for which the intellectual and spiritual quests became tools containing the 'soft power' of the state. Even Pope, Dryden till Basnett, Spivak and such other contemporary thinkers somehow get engaged into the global power games while contemplating over the issues of translation. Hence, the paraphrastic process perhaps gains more importance in their theorization. This is purely an empirical observation that those who were not engaged with any kind of empire-project had metaphrastic styles of translation and those who were engaged with some sort of empire-project had paraphrastic styles of translation both in their translation as well as in their theorizations on the translation. The cultures which preferred metaphrastic styles of translation proffer more of the translation tools (extensive efforts on lexicographical equivalence and word formation processes suitable to the translation requirements) which are missing in the Greek, Latin and other traditions of Europe. Even when the dictionaries and encyclopedias were made in Europe, they were not seen as important tools of translation. Extensive works on lexicography, as found in India and several cultures east to India, is a natural process transferring various ideas related to the concept contained in the texts of the cultures which are to be subjected to the translation process. Even otherwise, these cultures evolved various other lexicographical tools in order to construct the semantic universe of a concept - we may notice here the chanting of the 108/1000 names of a particular deity (Vishnu, Shiva and having various names of Buddha, Jain Tirthankaras etc.) The process of translation itself becomes reflective of the politically suggestive forms of thinking - translation is not merely 'source' or 'target' oriented but itself becomes the soft-toy in the hand of the political masters. It is almost like the 'clay model' of the world as we find in India - the same clay can be given various forms and the same 'clay-body' can get incarnated in various births. The text can be genetically mutated in its 'translated incarnations' in various forms in order to suit the need of the 'empire-project' if the 'paraphrastic translation' is preferred to the 'metaphrastic process'. In metaphrasing, as indicated by Cowell in the above citation, there is a possibility of retaining, reaching and recreating the original. Paraphrasing subsumes the original text without retaining any possibility of its recreation. The original may be lost forever - thus the 'empire-project' can be achieved.

Given the above discussed scenario on theory and practice of translation, we may have to understand how the language pairs chosen have been worked upon by the translators. In the cultures, which have worked metaphrastically, the language pairs are manipulated in a way so as to incorporate the style of the original. Cowell has illustrated this by giving the example of 'prepositions prefixed to verbal roots' in Tibetan in order to translate the Sanskrit texts. Thus calque or such other word transformation techniques which help the translator to present the original word containing a concept are important. Also, the explanations after the concept-words remain important. So, the tradition of commentaries becomes an important aspect of this translation. Here, we should not confuse the 'commentaries' as the modern 'footnotes and explanations'. Rather the 
commentaries are themselves extensive types of exegetical texts like bhasya, tika, curnika etc. The traditions which give more importance to the original text and try to retain it, whether intralinguistically or interlinguistically, in all the possible ways adopt the various translational and stylistic processes in order to achieve their goal. Similarly, the cultures which prefer paraphrastic translational processes adopted various stylistic processes for achieving their goal of receiving the text. In the process, the language pairs have been worked upon differently. They did not evolve the tradition of commentaries and exegetical texts as we find in the eastern culture - yet they worked extensively on the gain and loss in the translation. The translator is expected to transfer what he or she understands of the text. The target audience and its requirement have to be borne in mind along with the ideological inclinations of the translator. The translation thinkers have time and again argued in favour of paraphrastic translation with various ideological inclinations and decisions of the translator along with the theorizations on how ideas and concepts have been manipulated by the translator. It is natural that in the process, the translation theorists have worked upon the language pairs. However, it may be interesting to note here that the main thinkers of translation like Pope, Dryden, Basnett, Hatim, Steiner, Spivak and such others have not really worked on the language pairs. We may count Eugene A. Nida as perhaps the only U.S. based thinker who have theorized on the language pairs - there also more of his work in this context have been in the domain of linguistic morphology and less on the stylistic comparisons between the language pairs.

One may question at this point - why all these theorists of translation could comfortably avoid working on the language pairs and the comparison of stylistics of communicative expressions between the language pairs? Why most of the theorizations did not help evolve the actual translation process undertaken by the translators? The theorists have worked more on the ideology and cultural influences than on the actual processes of translation. This is an amusing aspect of the translation theorizations that the act of 'languaging' and 'contrastive style of conveying' have been ignored largely by the translation theorists. The only thinker available to the English-speaking world in the context of studying language pairs in terms of communicative styles is perhaps Vinay and Darbelnet. They had published their book originally in French in 1958. Translation essentially involved language pairs (whether within the same language as two different levels of language or between the two languages or between the two mediums of expressions which differ in their systems of sign and signification) and this lack of works on the language pairs in the entire $2 \mathrm{O}^{\text {th }}$ century may be baffling for us. The only book Vinay and Darbelnet was translated into English and published in 1995. A few other books of the same type using almost the similar categories may be found in some European languages (mainly French) but generally not in English. The English world has rarely produced any book which deals with language pairs with English as one language in the context of translation studies. An important reason for this also might be same 'empire-project'. The scholars writing in English are more concerned about the sense translation and the ideological concerns in the translation, or perhaps transcreation, of the text into English. Even such changes that might have happened in translation from English towards other languages have been rarely the object of study. Most of the Indian scholars of translation studies focus with similar agenda related to the 'empire-project' of the English speaking societies and the related ideological concerns. It is perhaps not out of place to mention here that most of the Indian language scholars also toe the same line and there are hardly any proper stylistic studies undertaken between the language pairs by the researchers of these departments of the Indian languages. The issue of official language status and related politics of language enter more into the domain area of study related to translation than actually working on the stylistic differences in communication patterns. Such studies, if undertaken, might help evolve paradigms for various translation tools including bilingual 
lexicons (of words and expressions) between the Indian language pairs. Unfortunately little has been available in such areas till date due to the emphasis on the studies related to the 'empireproject' related topics of research in translation studies.

The stylistic studies between language pairs, as traced earlier to the text by Vinay and Darbelnet available in English since 1995, may go back further to those thinkers who established the study on the static linguistics in the twentieth century. Vinay and Darbelnet write, "We have already observed that translators are more concerned with questions of options than with servitudes"(1995, pp. 16). Here the writer has made distinctions between the 'options' and the 'servitudes' in a language - by option, the writers means the variety of expressions available to the convey the same, rather similar, ideas in a particular language. 'Servitudes' are simply the well defined language rules, often explained by the grammarians or linguists studying a particular language. The translator has to accept these rules and thus this is the question of 'servitude' by the translator. The translator cannot change these rules - yet the options to chose from various expressions are available while translating. Vinay and Darbelnet explain it, "We would also say that grammar is the domain of servitudes whereas options belong to the domain of stylistics, or at least to a certain type of stylistics, namely that which Bally has treated in his Traité de Stylistique Française (1951). In fact, from our point of view and that of Bally himself (1952; see also: Malblanc 1963), it is possible to consider two types of stylistics."(1995, pp. 16-17) The authors have here indicated that the kind of work they have done have its origins in the work of the famous linguist Charles Bally. Charles Bally is well known to the English world as one of the editors of the $A$ Course in General Linguistics by Saussure. Bally's work is one of the pioneering works in the studies on stylistic features of language in the context of static linguistics which has been established by Saussure and subsequently followed by the entire linguistic fraternity of the twentieth century. Explaining further the concept of the two types of stylistics as relevant to the translation studies, Vinay and Darbelnet further write, "One seeks to isolate the means of expression of a given language by contrasting the affective with the intellectual elements. This is internal stylistics. The other seeks to identify the expressive means of two languages by contrasting them. We call this external comparative stylistics or comparative stylistics."(1995, pp. 17) The distinction between the 'internal' and 'comparative' stylistics made here are directly taken from the works of Charles Bally whose book has not yet been translated into English to the best of my knowledge. In French, he writes in the initial pages of his book about the 'variable proportions of intellectual elements and affective elements of our thought' as expressed in language. Ordinary usage of language has these two important aspects - ideas and sentiments. When ideas are expressed, it is more in the domain of 'intellectual elements' of language. When sentiments are expressed, it is more in the domain of 'affective elements' of language. Often in language the two get merged in the same expression. An example by Charles Bally is "Je suis étonné de vous rencontrer ici." (1921, pp. 7). This sentence would roughly translate as "I am surprised to meet you here. » In this sentence the idea is expressed through some words, yet the affective stylistic elements will be predominant in terms of the inflection of the voice, intonation etc. While translating, we have to keep in mind whether the equivalent sentence in another language will have similar affective elements when uttered in that language. The other equivalent sentence in French, as given by Bally, are - "Tiens! Vous êtes ici?" or "Comment! vous ici?" or "Vous?" or just « Oh !» may also sometimes express the same idea. All these variations of the same sentence "I am surprised to meet you here." exhibit the variations at the level of the 'affective elements' in the language. Detailed studies on such comparative stylistic elements between English and French have to be carried out so as to convey the idea with its affective elements. Such sentences do not come only from the literary works but these form part of our ordinary usage of language. The stylistic categories as understood by Charles Bally and 
ingrained in the Saussurean studies on language need to be delved into deeply so as to understand the expression of any idea in a given pair of language.

We may see on simple example of a sentence like "My name is John". The sentence will be translated into French as "Je m'appelle John", into Spanish as "Me llamo John". In German the sentence will be translated as "Mein name ist John" (if we translate literally) but a normal equivalent sentence in German would be "Ich heiße John”. In English the sentence "My name is John”, 'my' is a possessor of 'name' and then the sentence means literally "The name possessed by me is John". In the French or the Spanish sentence, the sentence would literally translate as "I call myself John". In the normal German sentence, the same concept is stylistically constituted differently and can be roughly translated as "I am known as John". 'Ich' is the nominative form unlike 'my' which is a possessive form of 'I'. Similarly in Russian, the sentence will be "Minya zovyut John." In this sentence, 'minya' is the accusative form of 'I' and 'zavyut' is the third person singular conjugated form of the Russian word whose approximate equivalent is 'addressed' in English. In terms of stylistics of these languages, we need to notice the way a simple sentence like 'my name is John' has been rendered in these languages, all from various branches of the Indo-European family of languages. In English, the emphasis is on the possession of a particular word for name; in French and Spanish, the emphasis is on the verb 'to call' in pronominal form for identify the name; in German the emphasis is on the way I am known (to others - this is implied though not stated clearly) and in Russian, the emphasis is on the way I am addressed (this implies the presence of others more clearly though not stated clearly). Such differences may be representative of the world view of the particular speech community also. Yet the main focus for us here, in terms of stylistics, is to understand how these languages differ from each other in terms of selection of words according to their parts of speech categories, in terms of their point of view of stating the fact and such others. To understand these two differences stated here, Vinay and Darbelnet uses the words 'transposition' (for change of the grammatical category in terms of the parts of speech) and 'modulation' (for change in the point of view while make statement representing the fact). Between the language pairs English - French/Spanish, we notice the difference in terms of 'noun' and 'verb' which is an example of 'transposition'. Between the language pairs English - German/Russian, we notice the difference in terms of 'noun' and 'verb' while the point of reference has also changed. The person named has been viewed in terms of how others know him or address him. So, this is an example of 'transposition' as well as of 'modulation'. Such comparative stylistic categories follow directly the methods of studying the styles of stating facts by Charles Bally. The purpose here is to identify the suitable methodology of undertaking the study of comparative stylistic features of a given language pair and the studies by Charles Bally in this Bally is perhaps by far the most important thinker.

In the context of the translation studies, the thinkers have lost mostly focus on the comparative stylistics studies between language pairs which are being worked upon in an act of translation. As we have argued, perhaps this is a consequence of the 'empire-project' which most of the advanced societies engaged in translating texts and translation studies have undertaken, whether consciously or unconsciously. Translation studies need to understand the Apollonian Dionysian dichotomy in terms of the stylistic features of the language pairs. The Apollonian would look at the logical, rational, power equation driven changes happening during the act of translation. Dionysian approach might help us understand the irrationalities in the stylistic features of language arising out of the age old traditions (traditions are often not considered scientific, though the views are changing with an advancement of science) of language, world views and philosophical outlook of social systems. Perhaps the works of Charles Bally and similar thinkers (going back to Ferdinand Saussure who is often designated as the father of Structuralism and the founder of the modern 
linguistics, though himself an exponent of the classical historical linguistics) have been ignored. Further studies need to be undertaken in this area which appears to have larger impact in theorizing on the act of translation and may lead to evolving comprehensive methods for evolving improvised tools for translation. Though it may be considered beyond the scope of this paper, it may not be out of place to state that tradition of Saussure which started with the study of the Indo-European group of languages along with a close study of the Sanskrit texts may further elucidate the stylistic categories of expression in ordinary as well as in literary usages of the language. Saussure himself having undertaken the studies of expressions related to the 'absolute genitive' in Sanskrit must have studied the texts related to the stylistic features written in the Indian traditions. We may find further beaconing lights for evolving the nuanced methodologies for understanding the art and science of translation if we undertake the study of such texts along with the alternative views on translation which emphasized more on the understanding of text than manipulating the text.

\section{References}

Apte, V. S. (1970). The Student's Sanskrit-English Dictionary (2nd ed.). Motilal Banarsidass.

Aśvaghosh. (n.d.). The Buddhacarita: or The Life of Buddha (E. B. Cowell, Ed.). https://www.ancientbuddhist-texts.net/Texts-and-Translations/Buddhacarita/Buddhacarita.pdf

Bally, C. (1921). Traité de Stylistique Française. Librairie C. Klincksieck.

Basnett, S. (2002). Translation Studies. Routledge.

Dolet, E. (n.d.). La manière de bien traduire d'une langue en aultre. http://www.gutenberg.org/files/19483/19483-h/19483-h.htm

Tulsidas. (Samvat 2074). Shri Ramcharitmanas. Gitapress Gorakhpur.

Upadhyaya, B. (1914). Sanskrit Shastron ka Itihas. Chaukhamba Vidyabhawan.

Upadhyaya, B. (2001). Sanskrit Sahitya ka Itihas (1oth ed.). Sharda Niketan.

Valmiki. (Samvat 2072). Shrimadvalmikiya Ramayan. Gitapress Gorakhpur.

Vinay, J., \& Darbelnet, J. (1995). Comparative Stylistics of French and English: A methodology for translation (M. Hamel \& J. C. Sager, Eds.). John Benjamins Publishing Company.

Vyas. (Samvat 2069). Adhyatmaramayan. Gitapress Gorakhpur.

World Digital Library. (2020, November 1). Saddharma Pundarika Sutra in Sixi Tripitaka. https://www.wdl.org/en/item/1787o/ 